\title{
29 SOCIO-TECHNICAL RESEARCH CHALLENGES IN UBIQUITOUS COMPUTING: The Case of Telematics
}

\author{
Ola Henfridsson \\ Viktoria Institute \\ John King \\ University of Michigan \\ Glenn Mercer \\ McKinsey Consulting \\ Dave Pavlich \\ Yellow Roadway \\ Walt Scacchi \\ University of California, Irvine
}

The modern automobile is an outstanding area of success for the diffusion of ubiquitous computing technologies (Walker et al. 2001; Want et al. 2002). The typical vehicle is equipped with a whole set of computer systems, controlling many of its takenfor-granted components such as the climate, engine, and transmission. Indeed, driving is an example of computer use that is weaved into the fabric of our everyday life (see Weiser 1991).

Telematics has lately emerged as a promising application area that combines vehicular computer systems and mobile network technologies for delivering valueadding services to both consumers and organizations. The services projected include fleet management, infotainment, remote diagnostics, vehicle management, and many more. While telematics is still in its infancy, industry analysts portray telematics as a fast-growing business domain for the coming years. Looking back at previous technology hypes, however, it can be assumed that the outcome of the current surge is 
dependent on the successful configuration and cultivation of business, organizational, and technological elements. In this regard, information systems researchers are well positioned for investigating the phenomena emerging with telematics.

The purpose of this panel is to explore a number of emerging telematic research issues with specific relevance for the field of information systems. Many of these issues are socio-technical in nature. This fact not only challenges IS researchers to apply their common stock of knowledge, but also to engage in developing novel theoretical and methodological approaches suitable for investigating the heterogeneous nature of telematics. Because telematic services typically rely on boundary-spanning mobility involving interconnected organizational and technological elements, the areas in which novel thinking is needed concur roughly with those of nomadic or ubiquitous information environments (see Lyytinen and Yoo 2002). Indeed, the development and use of telematic services often involve multiple user groups and interests, business actors and value propositions, as well as numerous coexisting open and proprietary technical standards utilized in different subsystems. Given this complexity, theoretical and methodological advancement can be necessary to understand how to conceptualize, design, and use ubiquitous applications and information systems for integrating the vehicle in the day-to-day practical problems of business, pleasure, and work.

We aim to stimulate discussion by presenting views on the following issues:

- Why is telematics an interesting application and challenging domain?

- How can we understand and analyze interactions between interconnected social and technical elements in telematic services?

- How can we deal with the methodological challenges involved in studying boundary-spanning mobility?

- How can the issue of multi-contextuality in ubiquitous computing be studied in the telematics context?

- What are the challenges in developing and designing large scale telematics infrastructures?

- What are the implications of telematics for transportation?

Each panelist will give a 10 minute presentation, raising particular issues and viewpoints engendered by their own experience of telematics research and practice. After the presentations, the audience will have an opportunity to discuss these and other viewpoints in what hopefully will be an interesting debate about challenges triggered by telematic applications and services.

Ola Henfridsson will discuss the multi-contextual nature of ubiquitous computing services. Ubiquitous computing envisions seamless access of mass-scale services over the multitude of contexts that users encounter in everyday mobility. However, to be successful, such computing must simultaneously be designed to provide transparent, integrated, and convenient support in localized use contexts. The issue of multicontextuality makes the design of ubiquitous computing services and environments a challenging endeavor. In particular, the discussion will focus on the socio-technical challenges involved in designing systems support for mobile device use in cars. The discussion will work as a basis for exploring the potential role of ubiquitous computing support technology for mediating use patterns of general, multipurpose mobile devices in specific, resource-demanding use settings. 
Glenn Mercer will discuss passenger car telematics in North America, as other panelists offer both a global perspective and insights into commercial vehicle telematics. As he sees it, the primary challenge facing telematics adoption--with all due respect for the wonders that the technology offers - is the weakness of the business case for it. We may indeed see telematics installations continue to rise in North America, but if this occurs only because car companies feel they must "give away" such installations gratis to consumers just to maintain competitive parity with rivals, then the technology must be declared a disappointment. We had hoped, in the early years of hype around this group of technologies, that there would have been a more attractive value proposition for drivers, so that they would pay for telematics systems at least in sufficient amounts to cover costs, if not to offer providers a profit. This has turned out-so far - not to be the case.

In speculating on the reasons for the low value drivers assign to telematics in North America, one can come up with several hypotheses:

- Market immaturity: perhaps too many people are just too unaware of what telematics can do for them (on the other hand, the United States has more telematics installations, via GM's OnStar, than the rest of the world combined).

- Regulatory issues: concerned about driver distraction, regulators and car companies have chosen telematics implementations that are safer but perhaps less attractive to customers than they otherwise might be, many navigation systems block route reprogramming unless the car is pulled to the side of the road and stopped, which is perhaps wise but certainly frustrating for the driver.

- Fundamental weakness in demand: the American grid pattern of road construction greatly erodes the value of navigation systems; rush-hour provision of traffic data from radio stations competes with onboard congestion updates; and ubiquitous cell phones (now being equipped with e-911) make some safety and security features of telematics redundant. Have we just not yet found the "killer app"?

- Competitive dynamics: does the sight of GM's OnStar system persistent failure to deliver profits (or even user renewal rates above 25 percent) dampen enthusiasm for other innovators to enter the market?

There may be other reasons for the lack of progress so far. Mr. Mercer would be very interested in input from attendees as to their hypotheses. He will also lay out a few thoughts on what developments might reinvigorate the telematics market for North American passenger vehicles.

Walt Scacchi is interested in discussing the interaction of different informatic or telematic regimes in venues like the personal automobile. Millions of new automobiles are being built and deployed worldwide each year, each as a mobile web of computing systems, sensors, control actuators, alarms, displays, and haptic interfaces, all dependent on vehicle power sources. This web is arrayed around applications addressing engine management and pollution control, safety and vehicle dynamics, driver dashboard ivehicle operating status) displays, and environmental and entertairment console. However, different organizational entities (design studios, automobile factories, car dealers, gasoline stations, and service centers) are associated with the design, manufacturing, sales, operation, and maintenance of these automobiles. Somehow a common or integrated regime of computing hardware, software, and network technologies must 
be developed that spans and interlinks these disparate organizations, their information processing systems, and information workflow. Now add to this (1) many automobile commuters also bring along cell phones, media players and mobile computers, which can increasingly interface to one or more of the existing automobile applications or embedded systems, and (2) the emergence of so-called intelligent roadways and traffic flow management systems that monitor collective patterns of moving vehicles through government agencies (or their contractors). Finally, add to this the reality of widely deployed computing systems needing to be increasingly updated or patched, together with some users actively seeking to modify these systems to improve vehicle performance. We now come to see that the automobile is rapidly becoming one of the most ubiquitous, computing system-intensive venues of everyday life, yet it is perhaps one of the least studied. How and why we should engage in studies of the automobile as a socio-technical interaction network thus serves as a point of discussion.

\section{REFERENCES}

Lyytinen, K., and Yoo, Y. "Research Commentary: The Next Wave of Nomadic Computing," Information Systems Research (13:4) 2002, pp. 377-388.

Walker, G. H., Stanton, N. A., and Young, M. S. "Where is Computing Driving Cars?," International Journal of Human-Computer Interaction (13:2) 2001, pp. 203-229.

Want, R., Pering, T., Borriello, G., and Farkas, K. I. "Disappearing Hardware," IEEE Pervasive Computing (1:1) 2002, pp. 36-47.

Weiser, M. "The Computer for the 21 st Century," Scientific American, September 1991, pp. 94104. 